\title{
artigos
}

DOI: 10.11606/issn.2318-8855.v3i3p157-170

\section{A identidade latino-americana em Cem Anos de Solidão (1967), de Gabriel García Márquez}

\section{Bruna Ferreira da Silva*}

Resumo: O artigo aborda o tema da identidade latino-americana no romance Cem anos de solidão (1967) de Gabriel García Márquez (1928-2014). A análise parte da ideia de que é possível utilizar uma fonte literária como documento para o historiador, ampliando o diálogo da História com a Literatura. A posição política de García Márquez, tendo como cenário a América Latina pós Revolução Cubana (1959), e sua proximidade ao governo e ideias de Fidel Castro, influem na proposta identitária construída pelo autor no romance, em concordância com o pensamento anti-imperialista de sua geração. Para García Márquez, a América Latina constitui sua identidade através da comum exploração e submissão que seus países enfrentaram diante das políticas intervencionistas estadunidenses, materializadas no romance através da empresa Companhia Bananeira, inspirada na United Fruit Company, símbolo da intervenção estadunidense, bem como da repressão aos trabalhadores locais e às ideias socialistas, recorte central deste artigo.

Palavras-Chave: Gabriel García Márquez; Identidade latino-americana; Cem anos de solidão; História.

\section{Introdução}

A formação de uma identidade, seja nacional ou mais ampla, como a latino-americana é um fenômeno social que pode ser expresso por meio da produção literária de uma época, tendo esta íntima conexão com seu contexto de produção (ao mesmo tempo em que este a influencia). É necessário ter a consciência de que a identidade, o "eu" só se sustenta perante o outro. Uma identidade é formada por dois ou mais lados e, além disso, ela não é natural nem

\footnotetext{
* Graduanda em História pela Faculdade de Filosofia, Letras e Ciências Humanas da Universidade de São Paulo (FFLCH/USP). Contato: brunaferreira992@gmail.com.
} 


\section{artigos $\mid e$}

Bruna Ferreira da Silva

tampouco estática, mas sim forjada e modificada de acordo com discursos de interesse de diferentes grupos. As identidades (nacionais), como lembra Stuart Hall, em $A$ identidade cultural na pós-modernidade, não são naturais, mas sim "formadas e transformadas no interior das representações" (HALL, 2011, p.49).

A literatura pode ser um documento para o trabalho do historiador, que se coloca como observador da obra em seu contexto de produção, circulação, recepção, de suas metáforas acerca do período e das ideias defendidas por seu autor. Cem anos de solidão traz uma grande carga de idealismo político e luta social encarnada por seu autor, Gabriel García Márquez, um intelectual engajado no discurso de uma unidade que ultrapasse questões culturais e se baseie antes de tudo em questões políticas e econômicas da América Latina com denúncias sobre a manipulação nestas duas esferas e também em termos históricos.

O trabalho com fontes advindas da literatura pode ser identificado nas pesquisas de Lucien Febvre e March Bloch na escola dos Annales. Na concepção tradicional as áreas eram consideradas opostas: uma tratava de fatos e a outra de ficção. Os Annales trouxeram para a História a possibilidade de ampliar sua base documental com romances, já que estes comportam em sua produção o contexto de sua época (FERREIRA, 2009). Assim, não é possível pensar a produção literária de um período sem contextualizá-la em sua situação política, econômica ou cultural, já que a uma obra literária pode ser a representação ficcional de uma realidade cara ao escritor.

Compreender a temática da identidade latino-americana por meio de um romance, tido, em primeiro momento, somente como ficção, e como ele pode ser visto como fonte para o historiador para levantar evidências sobre a cultura e o contexto de produção daquela obra que está no centro deste trabalho, que busca a integração entre dois campos de produção, a História e a Literatura.Cem anos de solidão é um exemplo de ficção que procura questionar e analisar os episódios da história da América Latina, relacionados à sua submissão econômica e política aos interesses internacionais.

Os discursos de Gabriel García Márquez, em Cem Anos de Solidão, afirmam sua posição de defesa da "latino-americanidade" como forma importante de questionar a dominação e 


\section{artigos $\mid e$}

\section{A identidade latino-americana em Cem Anos de Solidão (1967),} de Gabriel García Márquez

exploração sofridas por esta parte do continente desde os tempos de colônia até as intervenções externas dos Estados Unidos da América, já no século XX. O autor assumiu o papel de intelectual engajado e sempre deixou claro em discursos, trabalhos jornalísticos e romances, a defesa e a necessidade da união latino-americana frente à dominação dos países ricos. Em Cem anos de Solidão, Macondo, a cidade que além de cenário, é também uma personagem da trama, se torna uma metáfora de nossa história e a solidão dos personagens, representação do isolamento político, econômico e social, no qual, para o autor, os latinoamericanos sempre estiveram enredados.

Cem anos de solidão consolidou García Márquez como um dos mestres do realismo mágico latino-americano ${ }^{1}$. No livro, o autor relata acontecimentos ao longo dos anos no povoado de Macondo. Acompanha a trajetória da família Buendía, que participa de todo o processo político da região. Retrata guerras civis, disputas políticas entre liberais e conservadores, e inclusive fatos irreais se sucedem, dando um ar fantástico à narrativa. Estes contribuem para um questionamento acerca da construção da história e de seus agentes em episódios nos quais acontecimentos são esquecidos. A trajetória épica da estirpe Buendía por meio de conflitos políticos e ao mesmo tempo familiares, personagens seculares e uma mistura de realidade com fantasia compõem a obra, que promove interpretações e debates acerca do "mundo" latino-americano, de sua história e de suas relações com os agentes externos e com seus próprios atores históricos, na construção do seu imaginário e de suas projeções sobre o mundo e sobre si mesmos.

O romance tornou-se a expressão da posição política de Gabriel García Márquez e de seu alinhamento aos ideais da Revolução Cubana, fortificado após escrevê-lo, no que tange a ideia de sentir-se pertencente à América Latina e se identificar com os seus problemas. Assim como outros escritores de sua geração, defendeu a ideia de uma unidade latino-americana, superando o conceito de identidade nacional, discussão cara ao meio intelectual no século anterior, no período pós-independências.

\footnotetext{
${ }^{1}$ Sobre a relação de Gabriel García Márquez com o movimento do realismo mágico, ver Costa (2009).
} 


\section{artigos | e}

Bruna Ferreira da Silva

Este artigo busca discutir o conceito de identidade pensado por García Márquez e partilhado com seus contemporâneos como Mario Vargas Llosa e Julio Córtazar, como forma significativa para fazer frente ao imperialismo e intervenções estadunidenses na região.

\section{O espelho da obra: $O$ intelectual engajado}

\section{Ser intelectual na América Latina pós-Revolução Cubana (1959)}

A identidade subcontinental dominou o imaginário da geração do boom ${ }^{2}$ da literatura latino-americana - a primeira geração a atingir níveis relevantes de vendagem e reconhecimento internacionais - durante a segunda metade do século XX. A necessidade de buscar uma identidade regional vinha do incômodo dos intelectuais com a situação política da América Latina desde a virada do século XIX para o XX. A região se tornou um campo de disputas de estadunidenses e europeus.

Os primeiros lançaram mão de políticas intervencionistas e financiamento nos países latino-americanos a fim de evitar campanhas vindas da Europa, no início do século XX, com o objetivo de manter antigas zonas de influência (SMITH, 2009, p. 609). Ao perceber que a intenção dos Estados Unidos da América era fazer da região uma zona de interesses, os intelectuais passam a fazer frente ao alinhamento entre as duas partes.

O crescente poder dos Estados Unidos e sua criação de uma esfera de interesse na região do Caribe e América Central provocaram uma certa hostilidade na América Latina, especialmente entre os intelectuais. Alguns desenvolveram o conceito de civilização e cultura latinas versus anglo saxônicas e promoveu a ideia da unidade latina contra o 'Colosso do Norte' [...] $\mathrm{Na}$ década de 20, o antiianquismo era não só uma questão familiar nas universidades norte-americanas, onde se tornou parte do fervor emocional dos movimentos de reforma nacionalista, mas também uma característica regular do pensamento e retórica política de toda a América Latina(SMITH, 2009, p. 648-9).

\footnotetext{
${ }^{2}$ O Boom da Literatura Latino-americana foi um fenômeno literário e editorial entre as décadas de 1960 e 1970 , no qual a produção da região foi amplamente divulgada na Europa, atingindo níveis de vendas, até então, inéditos. Associada à jovens escritores como Gabriel García Márquez, Julio Cortázar, Mario Vargas Llosa, entre outros, suas obras têm caráter experimental, influenciadas pela vanguarda modernista e politizadas, devido ao clima político pós Revolução Cubana (1959), da região.
} 


\section{artigos $\mid e$}

\section{A identidade latino-americana em Cem Anos de Solidão (1967), de Gabriel García Márquez}

A oposição estabelecida pelos intelectuais de esquerda, que para Fidel Castro seriam representantes da Revolução tanto no meio acadêmico quanto nas artes, se firma na unidade como forma de evitar que os Estados Unidos estabelecessem seus interesses na região. A identidade latino-americana toma forma nos discursos da geração de 1960. Essas ideias estavam alinhadas ao que Fidel Castro defendia como o papel do intelectual latinoamericano. Para ele, não fazia sentido à produção que não tinha como objetivo ser interlocutora entre a população e as ideias da Revolução Cubana. Segundo Adriane Vidal Costa:

O fato de pertencer à esquerda se converteu em um elemento crucial de legitimidade da prática intelectual na década de 60. [...] Essa esquerda intelectual, nos anos 60, configurou-se como uma corrente organizada e coerente de ação política e de orientação ideológica. Segundo Castañeda, [Jorge Castañeda] essa organização e coerência foram possíveis porque os intelectuais possuíam bases de apoio, canais de expressão e eram escolhidos por governos (e o resto do mundo) como interlocutores (COSTA, 2009, p. 45).

Grande parte dos intelectuais que estiveram alinhados a Fidel Castro em um primeiro momento, se distanciaram da causa revolucionária, por considerarem que o governo cubano passou a censurar e determinar os rumos da produção literária, ignorando a liberdade dos autores na escolha de seus temas, condicionando-a apenas à política de Cuba, principalmente após o Caso Padilla ${ }^{3}$. García Márquez, por sua vez, manteve-se alinhado a Fidel, defendo-o de acusações de censura e afirmando que denúncias sobre a questão envolvendo o presidente eram planos dos Estados Unidos contra sua política.

\section{Gabriel García Márquez e a identidade de um artista comprometido.}

Gabriel García Márquez manteve-se ao lado de Fidel Castro e de seu governo mesmo quando a maioria dos intelectuais defensores da Revolução Cubana, em um primeiro momento, se afastou das políticas culturais cubanas. Tais políticas foram questionadas também por alguns cineastas que atuavam no Instituto Cubano del Arte e Industria

\footnotetext{
${ }^{3}$ Sobre o caso Padilla e a primeira grande ruptura dos intelectuais latino-americanos com o governo Cubano, ver Costa (2009).
} 


\section{artigos | e}

Bruna Ferreira da Silva

Cinematográficos (ICAIC). Esta instituição devia produzir filmes de acordo com as exigências do Ministério da Educação de Cuba, que tinha como objetivo transformar o cinema cubano em uma vitrine à "nova cultura revolucionária" da ilha. Muitos filmes tinham caráter didático, especialmente os curta-metragens, no que tange a nova política do governo. Tratavam de temas que envolviam heróis populares ligados à causa revolucionária e que eram levados a lugares mais isolados através do cine-móvil. (VILLAÇA, 2006).

O escritor aqui analisado, amigo pessoal de Fidel Castro, o defendeu publicamente das acusações de censura e serviu como um porta-voz do governo cubano em assuntos internacionais, como o Caso Padilla. García Márquez assumiu o papel de intelectual engajado levantado por Castro e transformou sua visibilidade enquanto escritor - fruto do boom da literatura - na possibilidade de propagandear as causas da Revolução, sobretudo no que tange o anti-imperialismo, e em especial o embargo econômico a Cuba que uniu a nova política latino-americana com o seu próprio pensamento político.

Será o anti-imperialismo que permeará sua ideia de identidade latino-americana, pensada como saída para enfrentar as intervenções estadunidenses e fazer com que a região alcançasse visibilidade e independências política, econômica e cultural. Diante de sua posição política, Gabriel García Márquez estabelece a identidade latino-americana, que se fará presente em seu romance baseada em questões econômicas. O autor encontra na esfera da economia, o discurso necessário para legitimar a unidade latino-americana, que, portanto, estaria apoiada no passado e presente comuns de exploração e submissão a interesses externos às suas necessidades.

O tema das identidades é uma discussão presente e relevante no meio intelectual latino-americano. A proposta de identidade forjada por Gabriel García Márquez e presente em seu romance se diferencia da concepção de identidade elaborada no contexto de formação dos Estados nacionais nos pós-independências. Neste momento, cada nação, ainda em formação estava em foco, e não toda a ampla região do continente colonizada por monarquias ibéricas, em seu conjunto. Nos idos dos anos 1960, toda essa região devia se opor ao inimigo do Norte. Partindo da consciência de comunhão de problemas, 


\section{artigos $\mid e$}

A identidade latino-americana em Cem Anos de Solidão (1967), de Gabriel García Márquez

independentemente das fronteiras nacionais, almejava-se superar a exploração imperialista que causava a submissão da América Latina. Ser latino-americano, segundo esta concepção, era ter consciência de que era necessário opor-se a essa dominação.

Apesar de lidar com um referencial de identidade regional, há uma dimensão mais ampla que abrange as representações do autor. Ao referir-se às dominações econômica e política, é de um fenômeno estrutural, que atinge toda a América Latina, que o autor está tratando. Assim, a identidade, pensada em termos regionais, não se confunde com regionalismo e ganha amplitude.

O reflexo do homem: A Companhia Bananeira como símbolo do imperialismo e a identidade latino-americana como resistência.

O romance de Gabriel García Márquez é repleto de representações da história latinoamericana, como apontam o peruano Mario Vargas Llosa e o poeta uruguaio Mario Benedetti em relação a Macondo (VIEIRA, 2012,p. 19), o povoado que é cenário para a narrativa e também uma metáfora da América Latina. A ideia de “macondismo"^ está presente na sociologia desde meados da década de 1970, através da ideia do sociólogo chileno José Joaquin Brunner. Em meio à mistura de realidade e ficção, o massacre dos trabalhadores da Companhia Bananeira ilustra o discurso anti-imperialista. A narrativa sobre a Companhia Bananeira e o episódio sobre o massacre de três mil trabalhadores durante uma greve é um exemplo interessante do uso da História por Gabriel Garcia Márquez para denunciar a intervenção estrangeira na região e o apoio dado pelos governos locais. Ao escolher o recurso de ampliar os números da história, três mil pessoas são mortas no romance, enquanto que os registros do episódio real giram em torno de mil (MARQUETTO, 2010, p. 55), García Márquez busca tirar o caráter local do acontecimento, criando a identificação através de

\footnotetext{
${ }^{4}$ Segundo o autor, o macondismo é uma forma de interpretar a América Latina através de sua literatura. Cem Anos de Solidão, assim como grande parte da literatura do Boom foi apropriado como um relato da realidade latinoamericana. In: VIEIRA, Felipe de Paula Gois Vieira. De Macondo a McOndo: os limites do Real Maravilhoso como discurso de representação da América Latina (1947-1996). Dissertação de Mestrado pela Universidade Estadual de Campinas. Instituto de Filosofia e Ciências Humanas, 2012. p, 22.
} 


\section{artigos $\mid e$}

Bruna Ferreira da Silva

elementos comuns a todos os países da região, principalmente, na região do Caribe e América Central.

\section{A história}

A United Fruit Company (UFCo), estava presente nas memórias de Gabriel García Márquez graças aos relatos de seu avô, um liberal que o fez criar um sentimento de aversão aos militares, ao contar-Ihe o caso da matança de trabalhadores grevistas, ocorrida no ano e local de nascimento de García Márquez, Magdalena - Colômbia, em 1928.

A empresa, fio condutor de sua posição anti-imperialista no romance, através de sua representação, a Companhia Bananeira, instalou-se na América Latina, ainda no século XIX, sob propriedade de Minor Cooper Keith, de uma rica família do Brooklyn, Nova lorque. Minor tornou-se o empresário mais rico da região, quando, em meados de 1890, além de instalar a multinacional produtora de frutas tropicais na região, concluiu a ferrovia que ligaria a produção de bananas ao porto, em Porto Rico.

Com filiais instaladas na Colômbia, Equador e Guatemala, serviu de mote não apenas para Cem Anos de Solidão, mas também para a Trilogía Bananera conjunto de livros que reúne as obras Viento Fuerte (1950), El Papa Verde (1954) e Los ojos de los enterrados (1960), escritas pelo guatemalteco Miguel Angel Asturias, que buscam resgatar os depoimentos de trabalhadores da região da Guatemala, que também sofreram com a exploração por parte da empresa (VERGARA, 2010). É o caso colombiano, caro a García Márquez, que nos interessa para entender o romance. Alinhada ao Partido Conservador, do presidente Miguel Abadía Méndez, que estava no governo naquele momento, a UFCo também se colocou contra movimentos de trabalhadores, tratados como ameaças comunistas. Até a greve de 1928, retratada em Cem anos de solidão, outros movimentos menores haviam acontecido, sem grandes repercussões, mas que serviram para chamar a atenção de movimentos liberais que passam a apoiar os trabalhadores.

Além das condições de trabalho, o pagamento dos trabalhadores da UFCo em cupons e não em dinheiro, o que os obrigava a comprar apenas nas lojas da própria companhia, levou ao crescente movimento trabalhista. Com a ausência de negociações por parte da UFCo, a 


\section{$\operatorname{artigos} \mid e$}

\section{A identidade latino-americana em Cem Anos de Solidão (1967),}

de Gabriel García Márquez

greve deflagrada em 10 novembro de 1928, inicialmente tratada apenas como mais um movimento menor, tomou proporções não esperadas pelas autoridades locais, que sob pressão do governo estadunidense e dos dirigentes da companhia, enviou suas tropas para Magdalena para conter o movimento visto como uma organização revolucionária de caráter comunista

Em 06 de dezembro, os trabalhadores se reuniram na praça da cidade de Ciénaga - em Magdalena para ouvir o pronunciamento do governador local, no entanto, o exército havia cercado a praça com metralhadoras. Sem que ocorresse nenhuma tentativa de negociação, e após a multidão se negar a se dispersar, exigindo a presença de representantes da UFCo, o governador deu a ordem e os militares abriram fogo, levando a morte de mais de mil trabalhadores que encurralados pelo pequeno espaço, não tiveram como fugir. As mortes foram anunciadas com satisfação para Washington, pelo embaixador estadunidense na Colômbia, Jefferson Caffery (MARQUETTO, 2010,p. 55).

Os movimentos e a posição do governo em relação aos trabalhadores levou a desestabilização do governo que já recebia investidas liberais, concretizada com a entrada de Alfonso López Pumajero, no governo, em 1934. A UFCo enfrentou crises e pragas que levaram a sua retirada da região de Magdalena, voltando a investir na produção local apenas em 1947; no entanto, no início da década de 1960, se retiraram novamente para a região de Urabá, em Antioquia, terceirizando a produção, comprada dos fazendeiros locais de Magdalena, sem manter administração sobre a produção (MARQUETTO, 2010, p. 57-58).

\section{A Ficção}

A narrativa sobre a greve em Magdalena, em 1928, se dá no romance, quando a Companhia Bananeira reprime uma greve de trabalhadores através do exército. Encurralados na praça principal de Macondo, onde esperavam o pronunciamento do governador e a negociação para o fim do movimento, trabalhadores da Co. Bananeira e suas famílias foram alvejadas por metralhadoras instaladas por toda a praça, matando cerca de 3 mil pessoas, entre adultos e crianças, que tiveram seus corpos amontoados em um trem, que os levaria 


\section{artigos}

Bruna Ferreira da Silva

para serem jogados ao mar. Assim, como a UFCo, na realidade, anunciou sucesso na negociação com seus trabalhadores, na ficção as autoridades locais de Macondo, anunciaram que o fim da greve se deu de forma pacífica.

Na noite anterior havia sido lida uma notificação nacional extraordinária para informar que os trabalhadores tinham obedecido à ordem de evacuar a estação e se dirigiam às suas respectivas casas em caravanas pacíficas (MÁRQUEZ, 2012, p. 340).

José Arcádio Segundo, um dos Buendía e trabalhador das plantações, além de ser um dos líderes sindicais, embora tenha sido jogado no trem com os corpos, sobrevive e ao voltar a Macondo é o único que tem consciência dos fatos, já que nenhum morador do povoado tem conhecimento sobre a greve e tampouco sobre os mortos ${ }^{5}$. A ausência de consciência no que tange o acontecimento por parte da população, pode ser vista como uma denúncia acerca da falta de comunhão dos problemas, bem como uma crítica aos responsáveis, ligados à empresa e ao capital externo.

[...] José Arcádio Buendía não falou enquanto não terminou de tomar o café.

-Deviam ser uns três mil - murmurou.

-O quê?

-Os mortos - esclareceu. - Acho que todos os que estavam na estação.

A mulher mediu-o com um olhar de lástima. 'Aqui não houve mortes', disse. 'Desde os tempos do seu tio, o coronel, não acontece nada em Macondo'. Em três outras cozinhas por onde José Arcádio Segundo passou antes de chegar em casa disseram a mesma coisa: 'Não houve mortes'. Passou pela praça da estação e viu as barracas de frituras amontoadas umas em cima das outras, e tampouco ali encontrou nenhum rastro do massacre. As ruas estavam desertas debaixo da chuva tenaz, e as casas fechadas, sem vestígios de vida interior (MÁRQUEZ, 2012, p. 343).

García Márquez retrata um fato em local e tempo determinados, mas abre mão de especificar o ocorrido de acordo com a "realidade dos fatos, tal como ela aconteceu". Não há marcadores temporais no romance, à exceção dos "cem anos", apontados no título. O autor

\footnotetext{
${ }^{5}$ O historiador Eduardo Posada Carbó discute as relações entre ficção e história no massacre das bananeiras de Cem anos de Solidão. O autor trabalha com a ideia de que a história colombiana pode ter absorvido o episódio narrado por García Márquez, de maneira que é a memória coletiva que é influenciada pela obra frente a história oficial da região e não a obra literária que busca as referências na história, já que os números tratados pelo romacistas são discutidos como reais. In: CARBÓ, Eduardo Posada. La Novela como Historia: Cien Años de Soledad y as bananeras. Boletín Cultural y Bibliográfico. Vol. 35. n 48. 1998.
} 


\section{artigos |e}

A identidade latino-americana em Cem Anos de Solidão (1967), de Gabriel García Márquez

cria um povoado fictício, ao invés de tomar um local existente e escolhe, ainda, ampliar o número de trabalhadores mortos, triplicando em relação ao acontecimento real, para dar a sua obra um caráter mítico. Os episódios que compõem o romance, especialmente este, aqui destacado, podem ser inseridos em diferentes épocas e países, pois não é o acontecimento da realidade que importa, mas sim, a sua representação, enquanto sintoma de uma dada configuração política, econômica e social. A repressão aos trabalhadores, seja na realidade ou na ficção, remete aos governos locais e aos interesses políticos e econômicos, por parte dos Estados Unidos, na região. Este retrato contempla todos os países latino-americanos, embora o fato que inspira o autor seja um episódio da história colombiana. História, memória e ficção andam juntas na narrativa de Cem Anos de Solidão.

\section{Considerações finais}

Cem anos de Solidão é produção de Gabriel García Márquez enquanto escritor engajado e nossa fonte primordial. É a narrativa ficcional levando em consideração o seu contexto de produção que tornou esta análise possível, e esta se trata de uma leitura possível da obra e de seu autor. A trama do romance reúne as posições políticas do escritor e suas memórias pessoais sobre acontecimentos caros à história da América Latina. Diferentes passagens do romance demonstram escolhas narrativas do autor, baseadas em fatos caros à região, como o episódio ficcional, tratado aqui, com maior atenção, do massacre dos trabalhadores da Companhia Bananeira fazendo referência à morte de grevistas da United Fruit Company, na Colômbia, em 1928, demonstrando a influência dos Estados Unidos nos governos locais bem como a negação de direitos sindicais.

As relações de poder são tema de interesse de Gabriel García Márquez, como o mesmo afirma no discurso Uma natureza diferente num mundo diferente do nosso, além de ser levantado em outras obras do autor, como O General em seu Labirinto e Ninguém escreve ao Coronel.A perda de poderes locais para as políticas intervencionistas estadunidenses é outro tópico do romance. Ele se constrói a partir da figura do Coronel Aureliano Buendía, que luta pela soberania na região, mas se rende ao tomar consciência de que não há motivos para 


\section{artigos $\mid e$}

\section{Bruna Ferreira da Silva}

lutar, já que outros poderes maiores tornaram Macondo um centro de influência. Aureliano é a expressão das lutas por independência, que se processaram na América Latina durante o século XIX e que se perderam diante da influência de políticas intervencionistas que tomaram a região e se tornaram um incômodo para os intelectuais da época, permeando sua produção, bem como a oposição aos estrangeiros que invadem a região, trazidos pela grande produção bananeira.

Este artigo estipulou como objetivo analisar episódios do romance Cem anos de Solidão, de Gabriel García Márquez, atentando para a forma como este autor desenvolveu no livro a ideia de existência de uma identidade regional, latino-americana, baseada em fatores políticos e econômicos, sem esquecer, mas se sobrepondo as questões culturais, base das identidades nacionais forjadas durante o século XIX. Esta posição estava ligada ao próprio contexto de produção da obra, pois os escritores levavam consigo as matrizes de pensamento de sua geração, que envolviam a posição política e o poder na América Latina, bem como as ideias da Revolução Cubana, um momento de possível virada na política e relações externas da região (AGGIO; PINHEIROS, 2012, p. 28). Nos anos 1960 e 70, muitos intelectuais se engajaram na luta contra a situação de "dependência" econômica e política da América Latina em relação a potências centrais ${ }^{6}$. Eles eram, via de regra, alinhados às ideias de esquerda e entusiastas da Revolução Cubana, de 1959. Para isso, partimos do pressuposto de que a forma como Gabriel García Márquez entendeu o problema identitário não despreza esta questão da posição de "dependência" econômica e política, tão em voga naquele período. Essa perspectiva acaba por enfatizar uma visão da região como una. As particularidades culturais de cada país não foram destacadas no romance, afim de se privilegiar o que há em comum a todos, isto é, a exploração e intervenção europeia e, especialmente, estadunidense.

\footnotetext{
${ }^{6}$ Assinalamos a palavra "dependência" entre aspas, para remarcar que se trata de um discurso dos anos 1960 e 70 cuja operacionalidade tem sido questionada, pelas implicações que ele traz. Ele alude a uma separação dual entre centro e periferia, que pode obscurecer as relações de exploração e dominação que ocorriam internamente no próprio continente; bem como pode levar a uma análise que desconsidera as diferenças de graus de desenvolvimentos entre os países da América Latina. Estes eram e são muito diversos em sua composição sócioeconômica. Para análise das críticas dualistas, vide: Hall (2011) e Rouquié (1992).
} 


\section{$\operatorname{artigos} \mid e$}

A identidade latino-americana em Cem Anos de Solidão (1967), de Gabriel García Márquez

\section{Fonte principal}

MÁRQUEZ, G. G. Cem anos de solidão. Tradução Eric Nepomuceno - 80a edição - Rio de Janeiro: Record, 2012.

\section{Fonte complementar}

MÁRQUEZ, G. G. Uma natureza diferente num mundo diferente do nosso. In. Eu não vim fazer um discurso. Tradução Eric Nepomuceno -Rio de Janeiro: Record, 2011.

\section{Referências bibliográficas}

AGGIO, A.; PINHEIRO, M. S. Os intelectuais e as representações da identidade latin-americana. In: Dimensões, vol 29. Franca: Revista do Programa de Pós-graduação da Universidade Estadual Paulista/ Unesp, 2012. Disponível em: http://www.periodicos.ufes.br/dimensoes/article/view/5396.

CARBÓ, E. P. La Novela como Historia: Cien Años de Soledad y as bananeras. Boletín Cultural y Bibliográfico. Vol. 35. n 48. 1998.

COSTA, A. V. Intelectuais, política e literatura na América Latina: o debate sobre revolução e socialismo em Cortázar, García Márquez e Vargas Llosa (1958-2005). Tese de doutorado defendida pela Universidade Federal de Minas Gerais, 2009.

FERREIRA, A. C. "A fonte fecunda". IN: PINSKY, Carla Bssanezi; LUCCA, Tania Regina de (orgs). 0 Historiador e suas fontes. São Paulo: Contexto, 2009

LOWY, M. O Marxismo na América Latina: Uma antologia de 1909 aos dias atuais. Tradução Claudia Schilling e Luís Carlos Borges. São Paulo: Editora Fundação Perseu Abramo, 1999.

MARQUETTO, S. R. United Fruit Company: Poder e influência na América Latina. Departamento de Ciências Econômicas da Universidade Federal do Rio Grande do Sul, 2012. Disponível em: http://www.lume.ufrgs.br/handle/10183/28378?show=full.

PINTO, J. P. A leitura e seus lugares. São Paulo: Estação Liberdade, 2004.

PRADO, M. L. C. Identidades Latinoamericanas. In: Historia General de America Latina. Volumen VII. Diretor: Enrique Ayala Mora. Ed. Trota, 2008.

. Uma introdução ao conceito de identidade. In: SAMPAIO, C. A. B.; GARCIA, T. C. (Orgs). Cadernos de Seminários de Pesquisa - Cultura e Políticas das Américas. Vl. 1. Assis: Unesp Publicações, $2009 . \quad$ Disponível em: http://historia.fflch.usp.br/ sites/historia.fflch.usp.br/files/CSP1.pdf. 


\section{artigos}

Bruna Ferreira da Silva

RIECHEL, H. J. A identidade latino-americana na visão dos intelectuais da década de 60. In: Estudos Ibero-Americanos. V. XXXIII, $\mathrm{n}^{\circ}$ 02. Pontifícia Universidade Católica do Rio Grande do Sul, 2007.

ROUQUIÉ, A. América Latina: Extremo Ocidente. São Paulo: Edusp, 1992.

SEIXAS, R. Identidade Cultural da América Latina: Conflitos Culturais Globais e Mediação Simbólica, EACH-USP, 2012

SMITH, R. F. Os Estados Unidos e a América Latina, 1830-1930. In: Leslie Bethell (org.) História da América Latina, volume IV: De 1870 a 1930. Tradução de Geraldo Gerson de Souza. 1 ed. São Paulo: Editora da Universidade de São Paulo; Brasília, DF: Fundação Alexandre de Gusmão, 2009.

SEVCENKO, N. Literatura como missão: tensões sociais e criação cultural na Primeira República. $2^{\text {a }}$ Ed. São Paulo: Editora Brasiliense, 1985.

VERGARA, A. M. F. A United Fruit Company e a Guatemala de Miguel Angel Asturias. Dissertação de Mestrado pela Faculdade de Filosofia, Letras e Ciências Humanas da Universidade de São Paulo (FFLCH-USP). São Paulo, 2010. Disponível em: www.teses.usp.br/.../AMINA_MARIA_FIGUEROA_VERGARA.pdf

VIEIRA, F. P. G. De Macondo a McOndo: os limites do Real Maravilhoso como discurso de representação da América Latina (1947-1996). Dissertação de Mestrado pela Universidade Estadual de Campinas. Instituto de Filosofia e Ciências Humanas, 2012.

VILLAÇA, M. M. O Instituto Cubano del Arte e Industria Cinemtográficas (ICAIC) e a política cultural em Cuba (1959-1991). Dissertação de Mestrado defendida pela Faculdade de Filosofia, Letras e Ciências Humanas da Universidade de São Paulo. São Paulo, 2006. Disponível: $\quad$ http://www.teses.usp.br/teses/disponiveis/8/8138/tde-06112006-174750/ptbr.php. 